\title{
When Occam's razor fails: hemipontine infarct on a background of previous surgery and radiotherapy for craniopharyngioma
}

\author{
Ian S Boon, ${ }^{1}$ Dilani Perera, ${ }^{1}$ John Ayuk ${ }^{2}$
}

${ }^{1}$ University Hospitals

Birmingham NHS Foundation

Trust, Birmingham, UK

${ }^{2}$ Department of Endocrinology, University Hospitals

Birmingham NHS Foundation

Trust, Birmingham, UK

Correspondence to

Dr lan S Boon,

ianboon@doctors.org.uk

Accepted 27 March 2016

\section{DESCRIPTION}

A 68-year-old man presented with a 5-day history of left-sided hemiparesis, dysphasia and abnormal gait.

His medical history included type 2 diabetes mellitus, hypertension and previous craniopharyngioma, treated with complex surgical debulking and subsequent radiotherapy 13 years earlier. As a result, the patient developed panhypopituitarism (gonadotrophin deficiency, growth hormone deficiency, adrenocorticotropic deficiency, thyrotropin deficiency and diabetes insipidus) and remained under the care of the endocrine team.

His treatment included replacement testosterone, growth hormone, hydrocortisone, levothyroxine, desmopressin and metformin for type 2 diabetes mellitus.

Clinical examination revealed left-sided hemiplegia with upper-motor-neurone signs and global dysphasia. Blood profile was normal. Given his history, it was initially felt this presentation was linked to his previous intracranial disease. However, an urgent CT of the head scan revealed an area of low attenuation in the right pons (figure 1). This was confirmed to be a right hemipontine infarct on MRI of the brain (figures 2 and 3).

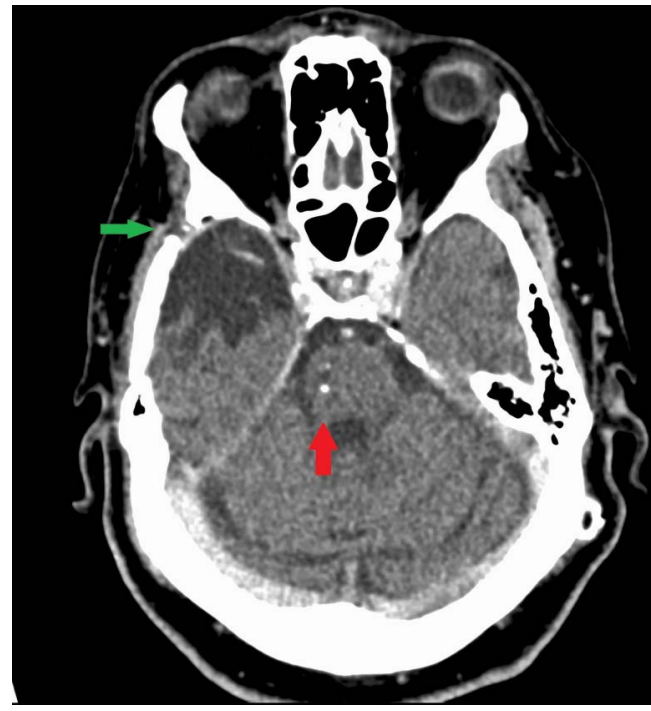

Figure $1 \mathrm{CT}$ of the head with contrast showing area of previous craniotomy (green arrow) from surgical debulking of previous craniopharyngioma. The new finding on this CT compared to previous imaging was an area of prominent low attenuation in the right pons (red arrow), which raised the suspicion of a small area of infarction.

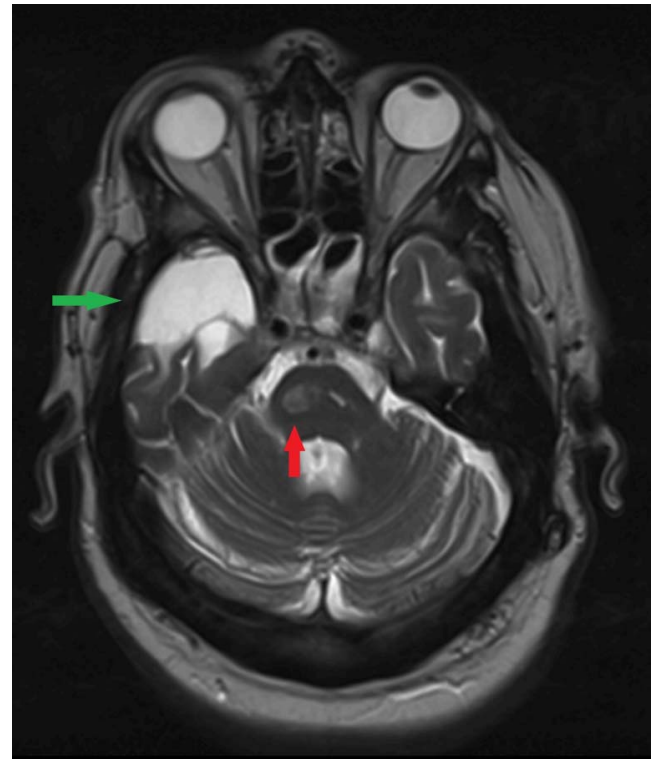

Figure 2 T2-weighted MRI of the head scan revealed an area of high signal (green arrow) within the right temporal lobe representing an area of stable chronic post-operative changes from previous surgical debulking of craniopharyngioma when compared to previous scans. New area of high intensity was noted within the right pons (red arrow) confirming an acute right hemipontine infarct without haemorrhagic transformation.

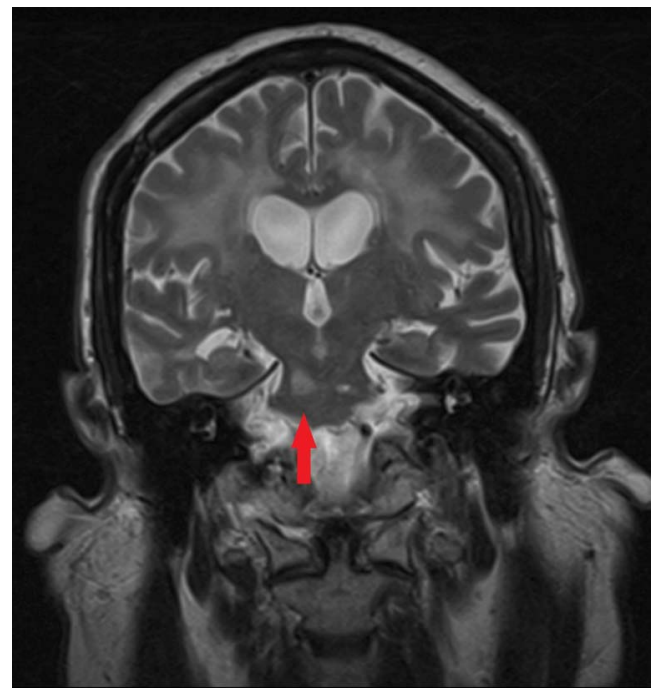

Figure 3 T2-weighted MRI of the brain scan with coronal view showing an area of high intensity within the right pons (red arrow), confirming acute right hemipontine infarct. 
The patient was admitted to the stroke unit and started on antiplatelet and secondary prevention medications.

\section{Learning points}

- Craniopharyngiomas are benign suprasellar tumours derived from embryonic pituitary tissue. ${ }^{2}$ Although benign in nature and slow-growing, complications arise due to mass effect on adjacent structures, and patients often present with headache, bitemporal hemianopia and symptoms of hypopituitarism. ${ }^{2}$ Patients with craniopharyngiomas should be managed by a multidisciplinary team and require long-term endocrinology input. ${ }^{2} 3$

- Review of the literature suggests postoperative treatment with radiotherapy of craniopharyngioma increases the long-term risk of stroke later in life. ${ }^{1}$ In our patient, there were added cardiovascular risks with existing hypertension and type 2 diabetes.

- Occam's razor is a useful tool in clinical medicine, to formulate a unifying medical diagnosis but, as shown in this case, sometimes patients can have the double jeopardy of presenting with two different medical diagnoses. Clinicians should exercise good clinical acumen and keep an open mind to ensure they are not missing a significant diagnosis.
Thrombolysis was not considered as he presented well over 4.5 hours from onset of symptoms. Following prolonged neurorehabilitation, he regained most of his motor function and was discharged home.

Radiotherapy treatment for craniopharyngioma has been shown to increase cerebrovascular disease risk and mortality rate. ${ }^{1}$ The mechanisms proposed are direct radiation damage to cerebral vasculature and pituitary hormone deficiency. ${ }^{1}$ Hypopituitarism occurs in 50\% of patients after a decade and the incidence increases with time from treatment. ${ }^{1}$ Interestingly, hypopituitarism occurs sooner if a higher dose of radiotherapy is used. ${ }^{1}$

Contributors ISB consented the patient, provided the title, reviewed the literature and wrote the manuscript. DP collected data and reviewed the manuscript. JA reviewed the literature, revised the manuscript and supervised the write-up.

Competing interests None declared.

Patient consent Obtained.

Provenance and peer review Not commissioned; externally peer reviewed.

\section{REFERENCES}

1 Ayuk J. Does pituitary radiotherapy increase the risk of stroke and, if so, what preventative actions should be taken? Clin Endocrinol (Oxf) 2012;76: 328-31.

2 Karavitaki N, Cudlip S, Adams CB, et al. Craniopharyngiomas. Endocr Rev 2006;27:371-97.

3 Gleeson H, Amin R, Maghnie M. 'Do no harm': management of craniopharyngioma. Eur J Endocrinol 2008;159(Suppl 1):S95-9.

Copyright 2016 BMJ Publishing Group. All rights reserved. For permission to reuse any of this content visit http://group.bmi.com/group/rights-licensing/permissions.

BMJ Case Report Fellows may re-use this article for personal use and teaching without any further permission.

Become a Fellow of BMJ Case Reports today and you can:

- Submit as many cases as you like

- Enjoy fast sympathetic peer review and rapid publication of accepted articles

- Access all the published articles

- Re-use any of the published material for personal use and teaching without further permission

For information on Institutional Fellowships contact consortiasales@bmjgroup.com

Visit casereports.bmj.com for more articles like this and to become a Fellow 